\title{
Comparative analysis of Azerbaijan's energy sector efficiency trend at the current development stage
}

\author{
Nurali Yusifbayli, ${ }^{1, *}$,Valeh Nasibov ${ }^{2}$ \\ ${ }^{1}$ Azerbaijan State University of Oil and Industry, 16/21 Azadliq, Baku, Azerbaijan \\ ${ }^{2}$ Azerbaijan Scientific - Research and Design-Prospecting Institute of Energetics, 94, Zardabi, Baku, Azerbaijan
}

\begin{abstract}
Methodological and practical aspects of the energy sector efficiency trend in various countries of the world and Azerbaijan for 2013-2017, based on the methodology presented by the World Economic Forum (WEF), are analyzed and considered in the paper. The basis of the methodology for evaluating the effective energy sector performance is the use of an energy triangle, where the vertices are Economic growth and development, Environmental sustainability and Energy access and security, where a set of indicators with their own weighting coefficients is used to evaluate each of subsystems. Naturally, the number of indicators and the weighting coefficients are adjusted in time in order to fully take into account all the features of the energy sector. The Azerbaijan's energy sector efficiency values for the period under review, taking into account all available indicators, are re-calculated, due to this fact the Azerbaijan's place in the world's ranking of countries has moved several positions higher.
\end{abstract}

\section{Introduction}

The basis of the methodology for evaluating the effective energy sector performance is the use of an energy triangle, where the vertices are Economic growth and development, Environmental sustainability and Energy access and security, where a set of indicators with their own weighting coefficients is used to evaluate each of subsystems. Naturally, the number of indicators and the weighting coefficients are adjusted in time in order to fully take into account all the features of the energy sector [1-6].

\section{Energy Architecture Performance Index of World}

For comparative analysis of changes in the Energy Architecture Performance Index for 2013-2017, the countries of the world were grouped into seven regions, for which the corresponding relationships were constructed [2]. The relationships of the Energy Architecture Performance Index subsystems of the European Union countries are shown below.

As is obvious from Figure 1, during the period under review, all 3 components of the energy sector efficiency in European countries have a positive growth trend, where the greatest growth is observed in the Environmental sustainability subsystem-17\%, Energy access and security subsystem-11\%, Economic growth and development subsystem - $6 \%$. At the same time, the subsystem values themselves as of 2017 are as follows: for Environmental sustainability - 0.7, Energy access and security - 0.82, Economic growth and development 0.61 .

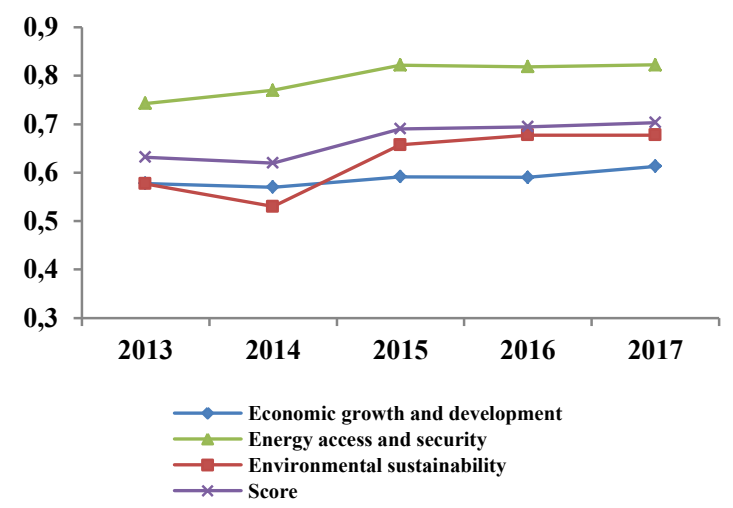

Fig. 1. Energy Architecture Performance Index of EU

In general, the energy sector efficiency in European countries increased by $11 \%$.

The curves for subsystems of efficient energy sector performance for the North America countries are shown in Figure 2. As is obvious from the figure, the Environmental sustainability subsystem has increased by $20 \%$ compared to 2013 , Energy access and security by $10 \%$, and Economic growth and development by $4 \%$. The subsystem values themselves as of 2017 are as follows: for Environmental sustainability subsystem 0.63 , Energy access and security subsystem - 0.66, Economic growth and development subsystem - 0.53 .

\footnotetext{
Corresponding author: author@e-mail.org
} 


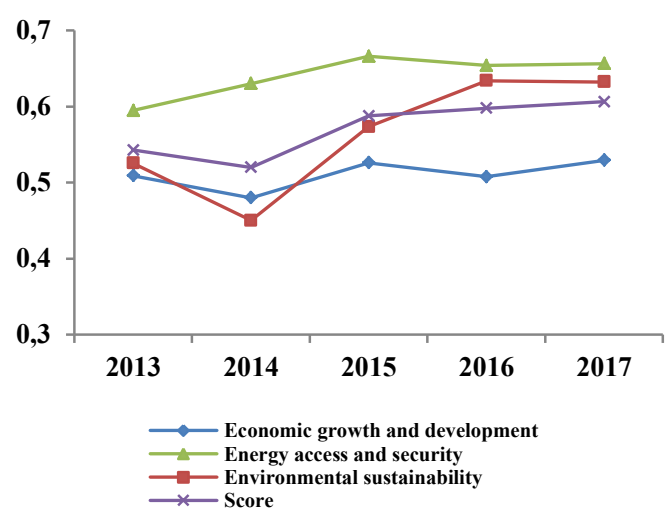

Fig. 2. Energy Architecture Performance Index of North America

On the whole, the energy sector efficiency for the North America countries increased by $12 \%$.

The energy sector performance efficiency subsystems curve for Middle East \& North Africa is presented in Figure 3.

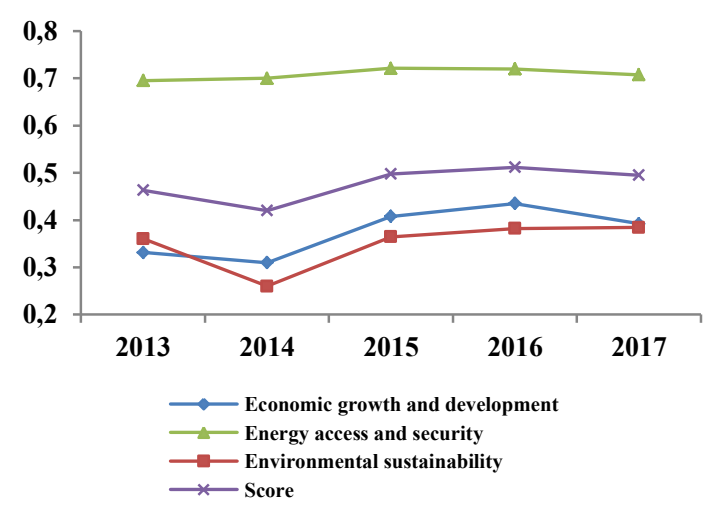

Fig. 3. Energy Architecture Performance Index of Middle East $\&$ North Africa

Unlike the EU and North America countries, the largest growth in the Middle East \& North Africa countries is observed in the Economic growth and development subsystem, which is $18 \%$. Low growth is observed in Environmental sustainability and Energy access and security subsystems, $7 \%$ and $2 \%$ respectively. These subsystem values as of 2017 are as follows: Economic growth and development - 0.39, Environmental sustainability - 0.38, Energy access and security-0.71.

On the whole, the energy sector efficiency for the Middle East \& North Africa countries increased by 7\%.

A different picture is observed in the BRICS countries. Although some drop of the Environmental sustainability subsystem value occurred in 2014, as shown in Figure 4, in 2015 it recovered up to 0.54 and remained practically constant during the last several years. Slight growth is also observed in the other two subsystems.

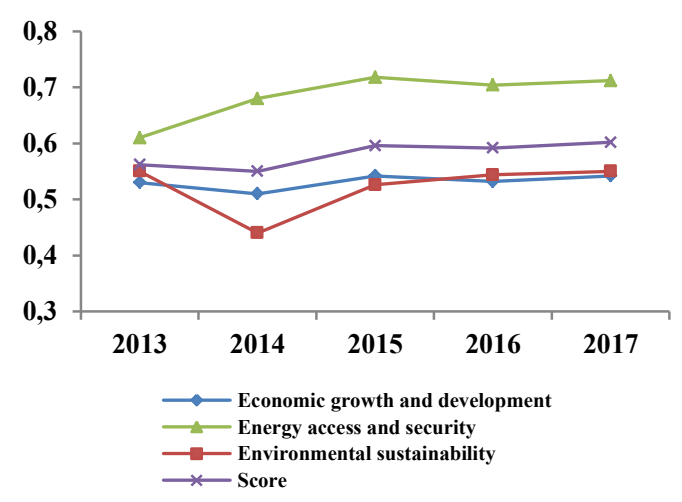

Fig. 4. Energy Architecture Performance Index of BRICS

In general, the energy sector performance efficiency of the BRICS countries also has a low growth compared to $2013-7 \%$.

In the ASEAN countries, slight growth is observed in the Economic growth and development subsystem by $16 \%$ and in the Environmental sustainability subsystem by $15 \%$, as is obvious from Figure 5 . At the same time, the subsystem values themselves as of 2017 are as follows: Sustainability environmental sustainability 0.57 , Energy access and security - 0.70, Economic growth and development -0.52 .

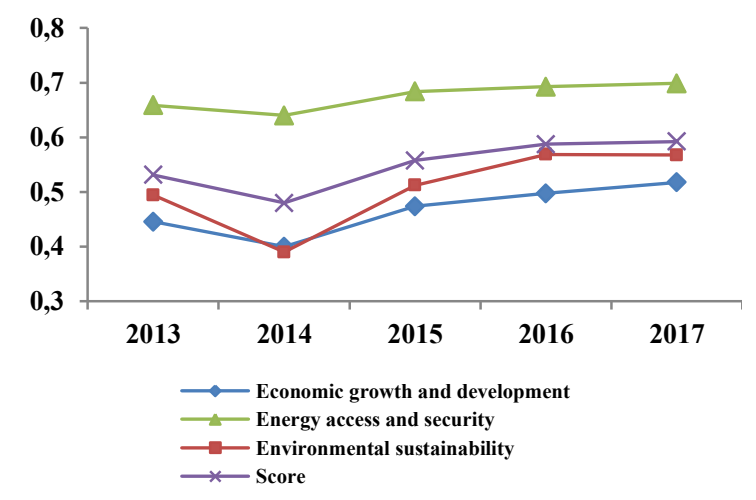

Fig. 5. Energy Architecture Performance Index of ASEAN

In general, the energy sector performance efficiency for the ASEAN countries increased by $11 \%$ compared to 2013.

Among the 7 regions considered, the most significant growth in the Economic growth and development and Energy access and security subsystems of effective energy sector performance is observed in the SubSaharan Africa countries, $24 \%$ and $33 \%$ respectively. At the same time, the subsystem values themselves in the Sub-Saharan Africa countries are still low compared to other regions, 0.47 and 0.39 respectively (Fig. 6). 


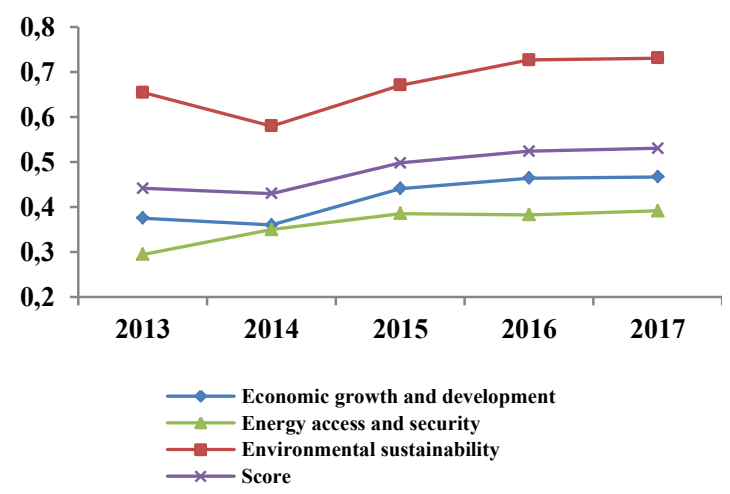

Fig. 6. Energy Architecture Performance Index of Sub-Saharan Africa

On the whole, the energy sector performance efficiency in the Sub-Saharan Africa countries also has the highest indicator among 7 regions, which has increased by $20 \%$ compared to 2013 .

In CIS countries, as is obvious from Figure 7, there is relatively small but steady growth in all subsystems. In 2014 a significant decline of the value to 0.48 happened in the Environmental sustainability subsystem, and some decline also has occurred in the Economic growth and development subsystem to 0.36 , which led to the decrease in the score to 0.51 .

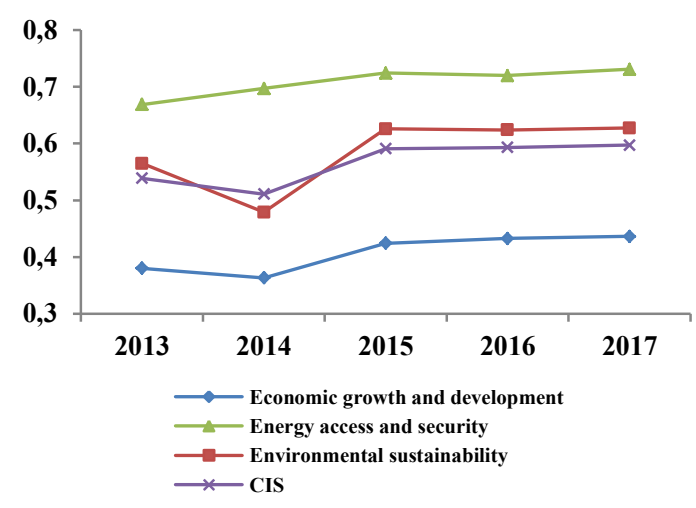

Fig. 7. Energy Architecture Performance Index of CIS

The values as of 2017 for the energy sector performance efficiency subsystems of CIS countries are as follows: for Economic growth and development 0.44, Environmental sustainability - 0.63, and Energy access and security -0.73 .

On the whole, the energy sector performance efficiency in CIS countries increased by $7 \%$.

Analyzing all regions, one can reach a conclusion that small but steady growth is observed in all subsystems of the energy sector performance efficiency. As is obvious from all the above curves and as shown in Figure 8, in 2014 the value of the Environmental sustainability subsystem dropped significantly in all regions, and in 2015 it recovered and remained almost unchanged over the past few years.

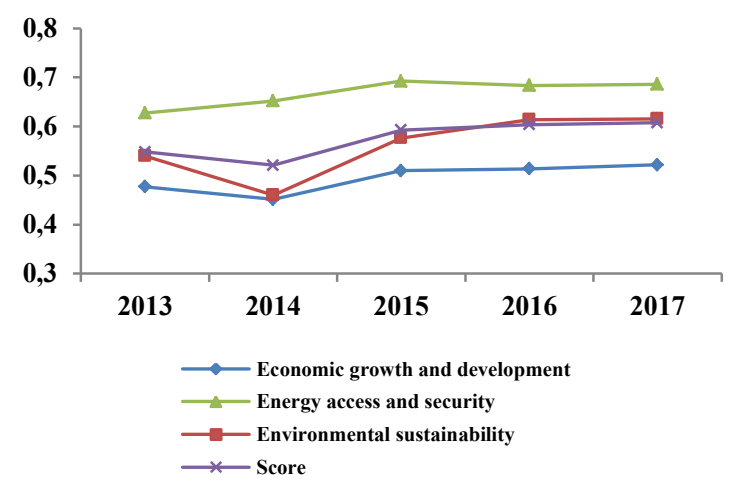

Fig. 8. Energy Architecture Performance Index of World

Values of world energy sector performance efficiency subsystems as of 2017 are as follows: Economic growth and development-0.52, Environmental sustainability-0.62, Energy access and security-0.69.

In general, the world energy sector performance efficiency for 2013-2017 increased by 11\%. The location of the curves of all 3 subsystems of energy efficiency around the world repeats the location of the corresponding curves for the EU, North America, ASEAN and CIS countries. As is obvious from the Figure 7, Economic growth and development (0.52) and Environmental sustainability (0.62) subsystems have significant potentials for the improvement. Due to the fact that the Energy access and security subsystem is at very high level in most countries of the world (0.7-0.82), the potentials for improving the state of this subsystem for the whole world are small (0.69).

\section{Energy Architecture Performance Index of Azerbaijan}

Similar studies have been conducted to determine the efficiency of Azerbaijan's energy sector performance [79].

As is obvious from Figure 9, during the period under review in 2013-2017, the efficiency of Azerbaijan's energy sector performance according to calculations of the World Economic Forum on the whole showed an increase of 14\%, while the "Economic growth and development" subsystem grew by $38 \%$, the "Environmental sustainability" subsystem by $12 \%$, and "Energy Availability and security" by $1 \%$.

It should be noted that according to the same calculations, the numerical values of the Energy Architecture Performance Index of Azerbaijan on the whole as of 2017 are 0.67 , and for the subsystems are $0.65,0.57$ and 0.79 respectively. 


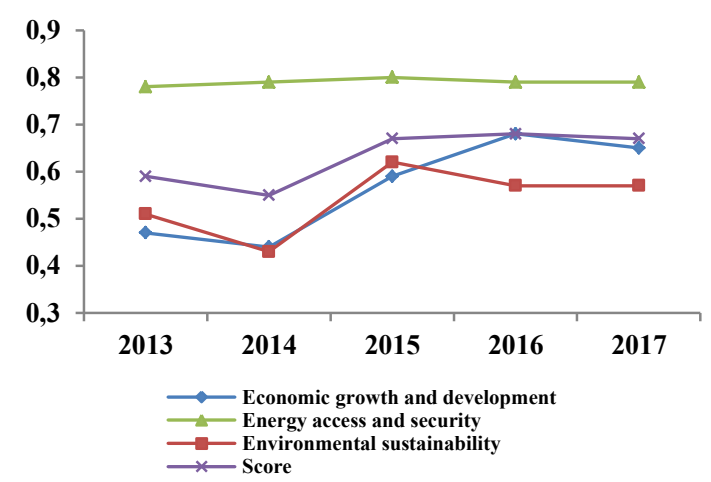

Fig. 9. Energy Architecture Performance Index of Azerbaijan

During the period under review, the efficiency of Azerbaijan's energy sector performance has significantly increased in the rating of countries. If in 2013 Azerbaijan was ranked $42^{\text {nd }}$ among 105 countries, then in 2017 it was ranked $36^{\text {th }}$ among 127 countries.

During the analysis it was found that the research of the World Economic Forum was incomplete, since the values of some indicators for evaluating the values of individual subsystems are not available, which led to inaccuracies in the assessment of both individual subsystems and the resulting value of the efficiency of the energy sector performance of Azerbaijan.

Below are curves of some indicators included in the subsystems of energy performance efficiency in Azerbaijan.

The chart of Energy intensity indicator, which is part of the Economic growth and development subsystem, is presented in Figure 10. As is obvious from the chart, the Energy intensity indicator value in 2018 increased almost by $25 \%$ compared to 2010 . It should be noted that this occurred mainly due to diversification of economy and sustainable development of non-oil sector [10-14].

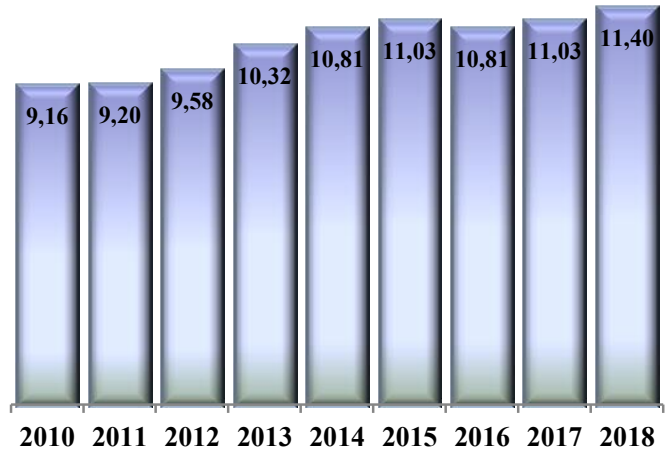

Fig. 10. Energy intensity (GDP per unit of energy use)

Another indicator from the Economic growth and development subsystem is Electricity prices for industry (US\$ per kilowatt-hour), which is not taken into account in the WEF report.

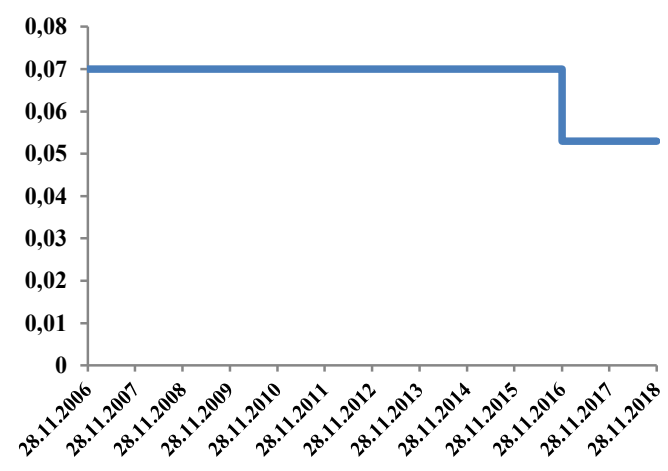

Fig. 11. Electricity tariff in Azerbaijan

The 'Electricity prices for industry' for Azerbaijan is presented in the Figure 11. As is obvious from the figure, since 2016 the price of electricity for industry has dropped by almost $25 \%$ from $\$ 0.07$ per $\mathrm{kWh}$ to $\$ 0.053$ per $\mathrm{kWh}$, indicating a high level of this indicator.

Another indicator of this subsystem is cost of Energy imports (\% GDP). As a result of the formal approach, the value of this indicator in the WEF report is shown as 0.28 , which worsens the resulting value of the subsystem under consideration. Analysis of the Energy imports indicates that the import of energy resources in Azerbaijan has increased in recent years (2016-2018) due to the increase in natural gas import. The energy balance of natural gas of Azerbaijan is shown in Table 1.

Table 1. Natural gas, mln.cubic meters

\begin{tabular}{|l|c|c|c|}
\hline & $\mathbf{2 0 1 6}$ & $\mathbf{2 0 1 7}$ & $\mathbf{2 0 1 8}$ \\
\hline Production & 18717.6 & 18186 & 19207.1 \\
\hline Import & 298.4 & 2109.9 & 1798.2 \\
\hline Export & 8049.1 & 8556.9 & 9911.8 \\
\hline
\end{tabular}

As is obvious from the Table 1, natural gas is imported not for domestic consumption of Azerbaijan, but to fulfill international obligations for its export, actually the imported natural gas is transit. It should be noted that because of this also the state of the Value of energy exports indicator (\%GDP) worsens, which in the WEF report for 2017 is indicated as $24.97 \%$, but actually it should be less.

Charts for some indicators included in the Environmental sustainability subsystem are given below. The chart for "Nitrous oxide emissions in energy sector" indicator, included in the Enviromental sustainability subsystem, is presented in Figure 12. As is obvious from the chart, the value of this indicator has significantly decreased in recent years, although there is some growth in 2017-2018. 


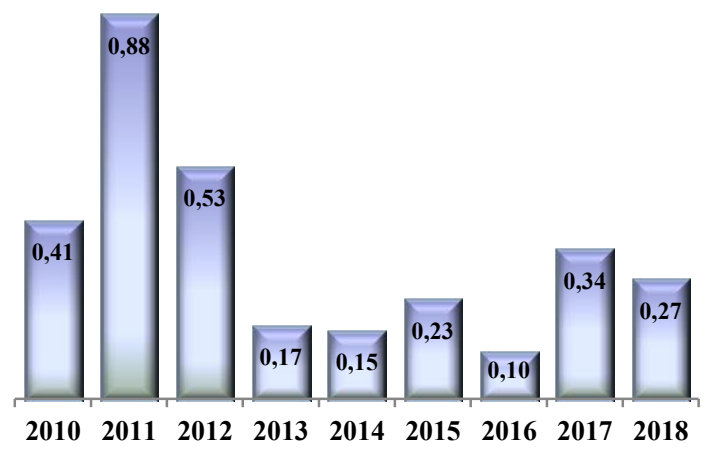

Fig. 12. Nitrous oxide emissions in energy sector, ton/population

Another indicator from the Enviromental sustainability subsystem is Methane Emissions in energy sector (metric tons of $\mathrm{CO}_{2}$ equivalent)/Total Population).

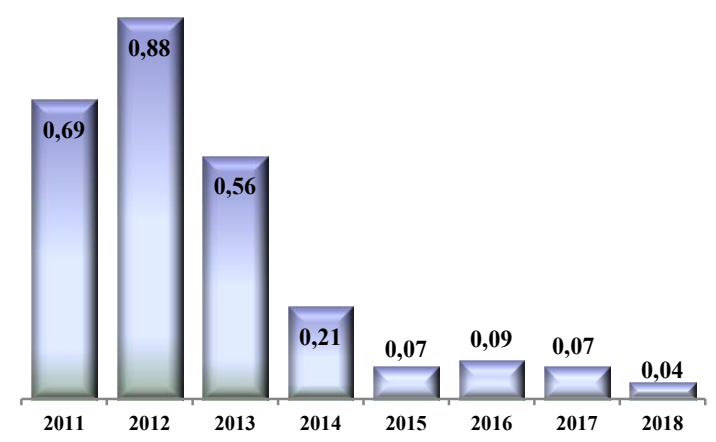

Fig. 13. Methane Emissions in energy sector, ton/population

As is obvious from Figure 13, Methane Emissions in the energy sector have decreased significantly in recent years.

The value of the "CO2 emissions from electricity" indicator in Figure 14 tends to decrease slightly, which is mainly due to the greater use of more efficient power plants for power generation.

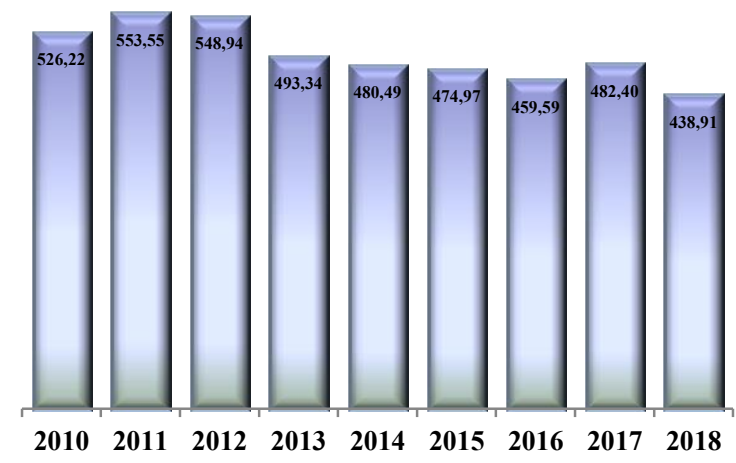

Fig. 14. $\mathrm{CO} 2$ emissions from electricity, gr/kWh

In the WEF report the Energy access and security subsystem is evaluated using 6 indicators. The most important for Azerbaijan are indicators Quality of electricity supply, Percentage of population using solid fuels for cooking and Diversity of total primary energy supply (Herfindahl Index). As shown above, energy resources imports mainly reflect the natural gas import, which is exported and actually is transit. Therefore, the values of the Import dependency and related Diversification of Import Counterparts indicators are calculated formally, and are not particularly important for evaluating the Energy access and security subsystem in Azerbaijan.

Percentage of population using solid fuels for cooking in Azerbaijan is presented in Figure 15. As is obvious from the figure, this indicator is in a very high level, conforming to gasification level in the country, although the value of this indicator in the WEF report is significantly worse.

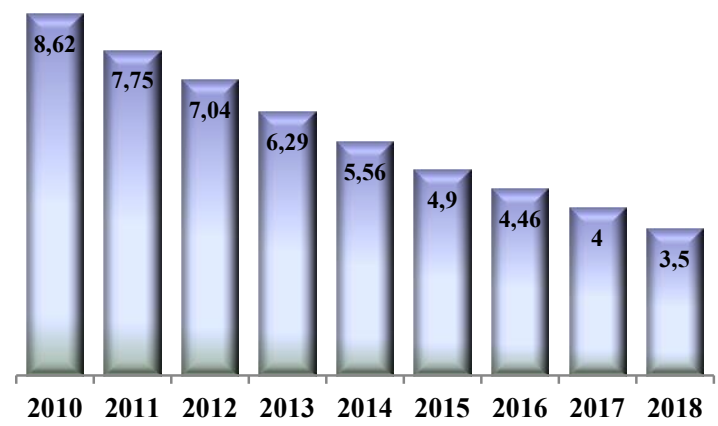

Fig. 15. Percentage of population using solid fuels for cooking, $\%$

Taking into account all available indicators included in the system of indicators for evaluating individual subsystems of energy performance efficiency in Azerbaijan, the values of energy sector performance subsystems were recalculated and their updated values were determined: for 2017 for the Economic growth and development subsystem-0.68, for the Environmental sustainability subsystem- 0.62 , for the Energy access and security subsystem- 0.8 , while the Overall score was 0.7

The energy triangle "Energy Architecture Performance Index of Azerbaijan" for 2017 with updated values of subsystems is presented below in Figure 16 [15].

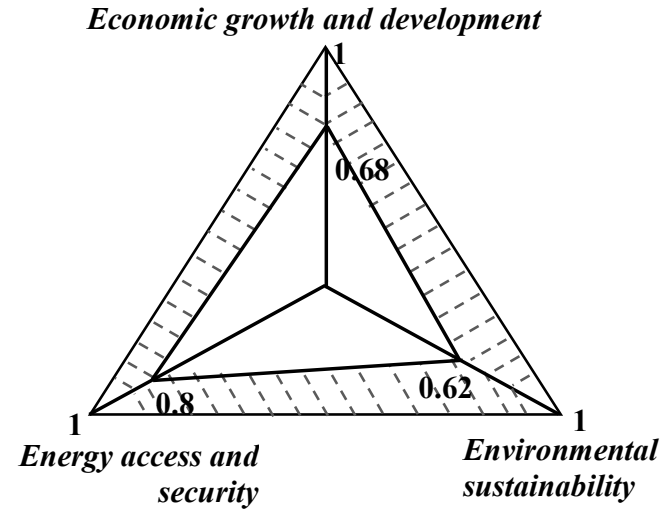

Fig. 16. Energy Architecture Performance Index of Azerbaijan 
As is obvious from the energy triangle, there are significant potentials for improvement of the state in the Environmental sustainability subsystem, quite large potentials are in the Economic growth and development subsystem and small potentials for improvement are in the Energy access and security subsystem.

\section{Conclusions}

1. The most characteristic features of energy sector performance in the selected regions are identified: in relatively developed countries (regions) the "Energy access and security" subsystem shows high values and "Economic growth and development" subsystem shows relatively low values, and resulting value of the energy sector performance efficiency of countries of the mentioned regions have a relatively middle position. This state of the energy sector performance efficiency is observed in the countries of the European Union (EU), North America, South Africa (BRICS), the Association of Southeast Asian countries (ASEAN) and CIS countries.

2. In less developed countries (South of Sahara (SubSaharan Africa)) a characteristic feature of energy sector performance efficiency is the relatively high value of the "Environmental sustainability" subsystem and the low values of the "Energy Access and safety" subsystem. At the same time, in the Middle East and North Africa (MENA) countries, high values for "Energy access and security" subsystem and low values for the "Environmental sustainability" subsystem are observed.

3. Recalculations of values of Azerbaijan's energy sector performance efficiency for the period under review have been performed, taking into account all available indicators included in the system of indicators for evaluating individual subsystems, due to this fact the Azerbaijan's place in the world rating could move several positions higher.

1. The Global Energy Architecture Performance Index Report 2013,

http://www3.weforum.org/docs/WEF_EN_NewEner gyArchitecturePerformanceIndex_ExecutiveSumma ry_2013.pdf

2. The Global Energy Architecture Performance Index Report 2014, https://www.accenture.com/keen/ acnmedia/accenture/next-gen/reassemblingindustry/pdf/accenture-global-energy-architectureperformance-index-report-2014.pdf

3. Global Energy Architecture Performance Index Report 2015,

http://www3.weforum.org/docs/WEF_GlobalEnergy Architecture_2015.pdf

4. Global Energy Architecture Performance Index Report 2016,

https://www.weforum.org/reports/global-energyarchitecture-performance-index-report-2016

5. Global Energy Architecture Performance Index Report 2017, https://www.weforum.org/reports/global-energyarchitecture-performance-index-report-2017

6. Fostering Effective Energy Transition A Fact-Based Framework to Support Decision-Making, http://www3.weforum.org/docs/WEF_Fostering_Eff ective Energy Transition_report_2018.pdf

7. Sustainable development of energy in Azerbaijan: gaps in energy efficiency and ways to eliminate them,

https://www.unece.org/fileadmin/DAM/projectmonitoring/unda/16 17X/A2.1_Implement_Natl_C S/Azerbaijan SE e.pdf

8. Azerbaijan Competitiveness Index, https://radingeconomics.com/azerbaijan/competitiv eness-index

9. Energy Architecture Performance Index 2017, Azerbaijan, https://reports.weforum.org/globalenergy-architecture-performance-index2017/economies/?doing_wp_cron $=1592298303.446$ $\underline{8669891357421875000 \# \text { economy }=\text { AZE }}$

10. Materials of State Statistical Committee of Azerbaijan Republic, https://www.stat.gov.az/

11. BP Statistical Review of World Energy 2019, https://www.bp.com/content/dam/bp/businesssites/en/global/corporate/pdfs/energyeconomics/statistical-review/bp-stats-review-2019full-report.pdf

12. World Energy Outlook 2018, https://www.iea.org/reports/world-energy-outlook$\underline{2018}$

13. BP. Energy demand by region, https://www.bp.com/en/global/corporate/energyeconomics/energy-outlook/demand-by-region.html

14. Global energy review 2020, https://www.iea.org/reports/global-energy-review$\underline{2020}$

15. N.A. Yusifbayli, V.Kh. Nasibov Determination of the Energy Architecture Performance Index of Azerbaijan, Methodological problems in reliability study of large energy systems, Issue 65 , Reliability of liberalized energy systems, pp. 446-456. 